Citation: A. Wan Nafi, M. Taseidifar, R.M. Pashley, B.W. Ninham (2020) Controlled Growth of Strontium Sulfate Particles in Aqueous Solution: Inhibition Effects of a Bubble Column Evaporator. Substantia 4(2) Suppl.: 95-107. doi: 10.36253/Substantia-1031

Copyright: (2020 A. Wan Nafi, M. Taseidifar, R.M. Pashley, B.W. Ninham. This is an open access, peer-reviewed article published by Firenze University Press (http://www.fupress.com/substantia) and distributed under the terms of the Creative Commons Attribution License, which permits unrestricted use, distribution, and reproduction in any medium, provided the original author and source are credited.

Data Availability Statement: All relevant data are within the paper and its Supporting Information files.

Competing Interests: The Author(s) declare(s) no conflict of interest.

\section{Controlled Growth of Strontium Sulfate Particles in Aqueous Solution: Inhibition Effects of a Bubble Column Evaporator}

\author{
Atikah Wan Nafi ${ }^{1}$, Mojtaba Taseidifar ${ }^{1}$, Richard M. Pashley $^{1, *}$, Barry $^{2}$ \\ W. NINHAM ${ }^{2}$ \\ ${ }^{1}$ School of Science, UNSW Canberra, Northcott Drive, Canberra, Australia \\ ${ }^{2}$ Department of Applied Mathematics, Research School of Physical Sciences, The Austral- \\ ian National University, Canberra, Australia \\ ${ }^{\star}$ Corresponding author: r.pashley@adfa.edu.au
}

\begin{abstract}
In the oil industry, strontium sulfate $\left(\mathrm{SrSO}_{4}\right)$ scale deposits have long plagued oilfield and gas production operations. This remains an unsolved problem. We here show how the bubble column evaporator (BCE) can be used to control aqueous precipitation from salt solutions. Mixtures of strontium nitrate and sodium sulfate in the BCE system were used to precipitate strontium sulfate at different degrees of supersaturation. The effectiveness of the BCE system was compared to standard mechanical stirring. The precipitation of strontium sulfate in both processes was monitored through turbidimeter, particle counting, Dynamic Light Scattering (DLS) and Scanning Electron Microscopy (SEM). The results show that the BCE system has a significant inhibition effect and so can be used to control precipitation growth rate, even from supersaturated solutions. This remarkable effect also provides new insights into mechanisms of crystallisation, of bubble interactions and mineral flotation.
\end{abstract}

Keywords: strontium sulfate, aqueous precipitation, nanobubbles, supersaturation, bubble column evaporator, particle growth rates, crystallisation, bubble interactions, mineral flotation.

\section{INTRODUCTION}

Coatings of partially soluble salts pose significant problems. The growth of deposits on the surface of industrial equipment like boilers, heat exchangers, wastewater treatment plants and in oil and gas drilling operations is always an issue. The scales generally contain sparingly soluble carbonates and sulfates of calcium, barium and strontium. The formation of scale deposits from mixing of two incompatible solutions, such as seawater and natural brines, presents a serious problem in industry, e.g. in the operation of oil fields, desalination plants and geothermal wells. Calcium carbonate and calcium sulfate scales are typical. Strontium sulfate $\left(\mathrm{SrSO}_{4}\right)$ scale is not so common. However, $\mathrm{SrSO}_{4}$ deposits have long plagued oilfield and gas production 
operations. Its removal by fast, spontaneous precipitation remains an unsolved problem in the oil industry, despite significant research efforts. ${ }^{1-8}$

Formation of sulfate scales reduces the diameters of pipes. This causes operational difficulties which may lead to additional capital cost and operating costs. ${ }^{9-12}$ Further, severe plugging of equipment causes loss of production, increases the cost of oil extraction and causes many safety issues. According to Howarth et al. ${ }^{13}$ wastewater facilities in the oil industry were simply not designed to handle the amount of strontium which can also include radioactive wastes. And indeed, the failure of equipment caused by strontium scale can result in safety issues due to its radioactivity. ${ }^{14,15}$ To try to mitigate these detrimental effects, research has focused on several treatment options. These are demineralization systems, thermal evaporation, condensation, and reverse osmosis. However, all these treatment processes suffer from difficulties in operation. ${ }^{16,17}$ For instance, the addition of reagents in chemical precipitation methods can result in separation problems, in which the acidic conditions produce toxic gases as by products. So, these processes have to be carefully monitored. $\mathrm{SrSO}_{4}$ scales are categorised as insoluble scales since they are not easily dissolved, and they are also relatively difficult to treat. The addition of acid to treat $\mathrm{SrSO}_{4}$ scales to reduce clogging and buildup of scale poses environmental issues. It also leads to the risk of interruption the whole operation. ${ }^{18-20}$ The reverse osmosis membrane technique offers another common treatment method. However, exposure to high salt level concentrations present in feed water can readily block the pores of the membrane sheets and so fouls the expensive membranes. These have to be regularly cleaned or replaced. ${ }^{21-23}$ This leads to low efficiency of the process, high maintenance costs and a decrease in the quality of water produced. To protect the membrane and maintain the efficiency of the process, regular feedwater pre-treatment is essential. This again increases costs, besides complicating the process. ${ }^{24,25}$ Currently, there are no reports on efficient water treatment which affordably and simply inhibits $\mathrm{SrSO}_{4}$ particle growth.

Prior to disposal, wastewater treatment typically aims to maximize the concentration of contaminant using low cost energy, for example, from industrialwaste vent gases, solar heat or wind turbines. These energy sources could be used with the BCE system, which concentrates wastewater and at the same time inhibits the growth of precipitate particles, as has recently been reported ${ }^{24,25}$ in work that precedes ours. It was discovered that precipitation inhibition naturally occurs in the bubble column evaporator process for supersaturated solutions of calcium sulfate. In this process, a con- tinuous, high density, flow of rising bubbles apparently disrupts the growth of nano-particles, even in supersaturated solutions. Comparison with standard mixing methods indicates that the BCE process offers a cost effective and simple method to create precipitation inhibition. ${ }^{26}$ There, precipitated particles of $\mathrm{CaSO}_{4} \cdot 2 \mathrm{H}_{2} \mathrm{O}$ were maintained at a steady size of $<100 \mathrm{~nm}$ within a BCE, whilst stirred solutions, at the same supersaturation rate (of about 32 times the solubility product) formed particles with sizes increasing rapidly above 1 $\mathrm{mm} \cdot{ }^{26}$

Apart from scale deposit problems in the oil industry, $\mathrm{SrSO}_{4}$ is a multifunctional inorganic material used in various chemical applications, such as in electronics, ceramics, pigments, cosmetics, paper making and as a compound used for thermo-stimulated luminescence. ${ }^{27,28}$ This study is aimed at the determination of suitable treatments to prevent scale formation, and in order to do this it is important to understand in depth the precipitation reaction of $\mathrm{SrSO}_{4}$ in the first place. Studies on the production of fine particles, through precipitation, have received vast attention with a view to controlled production of fine particles. Nanoparticle materials can be obtained by several methods; such as, precipitation, hydrolysis, electrolysis etc. Compared with other methods, the precipitation reaction has potential advantages of homogeneity, high productivity and controllability of the process..$^{29,30}$ However, the stirred tanks often used in the precipitation process can produce particles with a broad size distribution due to inhomogeneous mixing combined with rapid and spontaneous reaction of the mixed components. ${ }^{31,32}$ The formation of particles of small size is often followed by agglomeration, which hinders the ability to produce fine particles. Few studies on simple, effective, additive-free methods for controlled precipitation have been reported. This paper is one such new method. Some unresolved fundamental issues on mechanisms of crystallisation come up in the course of this research that will leave for later discussion in the Appendix.

One of such experimental studies reports the effect of a magnetic field in combination of temperature on the precipitation of insoluble salts of alkaline earth metals, such as carbonates of calcium, strontium and barium, which were precipitated from supersaturated conditions. The structure of $\mathrm{CaCO}_{3}$ crystals were studied by a combination of X-ray diffraction, optical microscopy and fluorescence. All show that the application of a magnetic field with about $0.4 \mathrm{~T}$, leads to inhibition of particle precipitation. ${ }^{33}$ It was discovered that insoluble salts, especially $\mathrm{CaCO}_{3}$, when the solution underwent magnetic treatment for about 15 min before mixing caused a sup- 
pression of particle nucleation and increased the crystal size, with a reduction in crystal number density. Precipitation of supersaturated salt solutions can be retarded through a combination of high magnetic fields and high temperature of $60{ }^{\circ} \mathrm{C} .{ }^{34}$

In comparison with our experiments, the magnetic field generated in the magnetic stirring system used was likely to be too low to have any significant effect. In addition, it was observed that in the stirring system using a magnetic bar, the particles precipitated readily and in a shorter time and with a higher growth rate.

The BCE process, used in this work, exhibits an excellent ability to control the $\mathrm{SrSO}_{4}$ precipitation. The process employs vigorous mixing to form a uniform solute concentration. From this a more controlled precipitation process was achieved than from a standard mixing method. This study shows that the BCE method can be used to successfully inhibit precipitation of $\mathrm{SrSO}_{4}$ from supersaturated solutions and reduce the rate of particle growth. The inhibition phenomenon is clearly of much wider application than for $\mathrm{SrSO}_{4}$. Based on these experimental results, the BCE process could also be used for reducing precipitation of $\mathrm{SrSO}_{4}$ and other nanoparticles scales that have potential applications especially in the oil and gas industry and in industrial water treatment plants.

\section{MATERIALS AND METHODS}

\subsection{Materials}

The salts $\mathrm{Sr}\left(\mathrm{NO}_{3}\right)_{2}$ and $\mathrm{Na}_{2} \mathrm{SO}_{4}$ used in these experiments were analytical reagents with purity level $\geq 99 \%$, purchased from Sigma- Aldrich. Double-distilled water, Milli-Q water and purified bottled drinking water, 'Woolworths Select Mountain Spring', were used to prepare the salt solutions and to produce a low particle count comparison. At room temperature, the MilliQ water had a conductivity of less than $3.0 \mu \mathrm{S} \mathrm{cm}-1$ and $\mathrm{pH}$ of 7.06. All concentrations are given in molarity $(\mathrm{M})$ units at room temperature.

\subsection{Precipitation processes}

Figure 1 shows a schematic diagram of the BCE system, in which bubbles are sparged into the mixed salt solutions containing $\mathrm{Sr}\left(\mathrm{NO}_{3}\right)_{2}$ and $\mathrm{Na}_{2} \mathrm{SO}_{4}$ and also a standard stirring system to compare the precipitation process for $\mathrm{SrSO}_{4}$ at $25^{\circ} \mathrm{C}$. The air gas is pumped from an air pump (Hiblow HP40, Philippines) that passes through a silica gel column to dehumidify. A flow meter

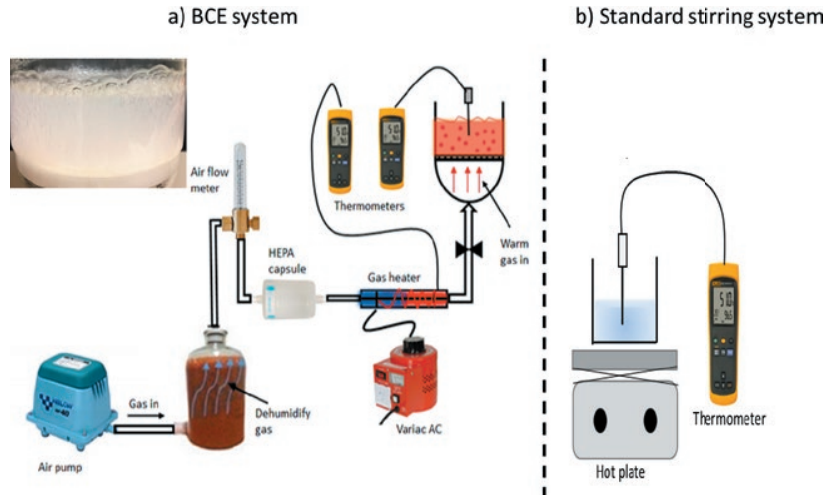

Figure 1. Schematic diagram of the bubble column evaporator (BCE) system and a photograph of a bubble column (a) and standard stirring process (b) for mixing $0.0015^{2} \mathrm{M}^{2} \mathrm{Sr}\left(\mathrm{NO}_{3}\right)_{2}$ and $\mathrm{Na}_{2} \mathrm{SO}_{4}$.

is used to control the flow rate of the inlet air which was placed after the desiccator. Normal air was used in the $\mathrm{BCE}$, which was pre-filtered using a Whatman large High Efficiency Particulate Air (HEPA) filter capsule to filter inlet air. The inlet air passes continuously through the BCE set up, which was operated within a filtered air, laminar flow cabinet. The HEPA capsule can retain 99\% of particles below $0.3 \mathrm{~mm}$. The air flow was passed through the gas heater to provide the required temperature. The heater temperature was controlled by a digital variac power supply and maintained using a thermometer (Control company 4000 Traceable). Then the controlled hot gas flow was pumped into the bubble column containing the mixed salt solution. To start the precipitation process, the concentration of salt solutions was set at a suitable supersaturation level. The bubbles produced in the columns were fairly uniform within the size range of about 2-4 $\mathrm{mm}$.

For comparison with the BCE experiment, a standard stirring experiment using the same salt solutions at the same temperature were operated using different cylindrical magnetic bars with lengths of 2 to $5.5 \mathrm{~cm}$ at different stirring rates of $0,120,240$ and 480 revolutions per min (rpm). The liquid samples from the BCE system and standard stirring systems were taken directly using syringes and filtered through Whatman Millipore 0.22 $\mu \mathrm{m}$ at different times for further characterisation and by analysis of the removed dry particles.

\subsection{Analytical methods}

The induction and precipitation growth of $\mathrm{SrSO}_{4}$ particles over time were monitored by turbidity measurement (HACH 2100AN Turbidimeter). The solution 
turbidity at $0.2 \mathrm{NTU}$ was taken as the onset of precipitation. This is a useful indicator because the clear water and solutions without obvious precipitates normally gave turbidity values less than 0.2 NTU. A Spectrex Laser Particle Counter (model PC-2300) was used to determine the purity of the solutions. The particle counter with detection size range $0.5-100 \mu \mathrm{m}$ was able to detect the presence of contaminant particles that may affect the precipitation process. The presence of these particles in the solution prepared using distilled water, bottled water and Milli-Q water when filtered by the Whatman Millipore $0.22 \mu \mathrm{m}$ was tested before each precipitation experiment.

In addition, a Malvern Zetasizer (Model ZS) with detection size range $0.3 \mathrm{~nm}-10 \mu \mathrm{m}$ was used to monitor the growth of the precipitated particles. $1 \mathrm{~mL}$ samples were collected into polystyrene cells using a syringe for dynamic light scattering measurement using the Malvern Zetasizer. Solution samples were filtered before the DLS analysis when precipitation became visible. Then the filtered samples were kept in the open air to dry completely before examination with a FEI Quanta QEMSCAN Scanning Electron Microscope (SEM), to study particle morphology.

\section{RESULTS AND DISCUSSION}

\section{1. $\mathrm{SrSO}_{4}$ precipitation}

The precipitation process typically starts when the concentration of a compound in solution is greater than its solubility, i.e. from a supersaturated solution. In the case of the reactive precipitation of $\mathrm{SrSO}_{4}$, as in this work, the reaction is given, by convention, as

$\mathrm{Sr}^{2+}{ }_{(\mathrm{aq})}+\mathrm{SO}_{4}{ }^{2-}{ }_{(\mathrm{aq})} \rightleftarrows \mathrm{SrSO}_{4(\mathrm{~S})}$

The precipitate of $\mathrm{SrSO}_{4}$ is produced when the product of the concentrations of $\mathrm{Sr}^{2+}$ and $\mathrm{SO}_{4}{ }^{2-}$ ions is greater than the solubility product. The precipitation of $\mathrm{SrSO}_{4}$ and its morphology was determined using SEM to determine the formation of $\mathrm{SrSO}_{4}$ precipitated from a stirred solution and from a BCE.

The supersaturation degree (denoted S) of a $\mathrm{SrSO}_{4}$ salt solution is defined as:

$S=\frac{\left[\mathrm{Sr}^{2+}\right]\left[\mathrm{SO}_{4}^{2-}\right]}{K_{S P}}$

Where $K_{s p}$, the solubility product, equals $\left[\mathrm{Sr}^{2+}\right]_{\mathrm{eq}} \mathrm{x}$ $\left[\mathrm{SO}_{4}{ }^{2-}\right]_{\mathrm{eq}}$ which is the equilibrium product at the solubility limit, assuming ideal conditions. All ion activity coefficients are assumed equal to 1 and hence the activities of all the ions are equal to their concentration. Because of the dilute concentrations involved, this assumption is reasonable. Besides the main factor of supersaturation level, other factors can affect the precipitation process: impurities, temperature, contact time, $\mathrm{pH}$, agitation intensity and overall ionic strength. ${ }^{35-39}$ In this study, the main factors were the degree of supersaturation, purity of background solution and the BCE process as it affects precipitation compared with simple solution stirring.

Several studies have discussed the effect of turbulence on morphology, scale deposition and minimal inhibitor concentration. ${ }^{40,41}$ However, there is no consistent finding on the effect of turbulence on scale deposition. Barium sulfate precipitation was conducted under turbulent conditions and compared with lamina precipitates inside oilfield pipes. The results show that there is no difference in sulfate precipitation kinetics without inhibitors (polymeric based additives) in both conditions. ${ }^{42,}{ }^{43}$ The present work using the BCE and standard stirring system was conducted inside a laminar flow cabinet. The results obtained might be developed for application to the $\mathrm{SrSO}_{4}$ precipitation problem in the oil and gas industries.

Particle counts obtained using the Spectrex counter were used to determine the purity of water samples. It was found that the particle count of all types of water samples inside the laminar cabinet are more stable compared to samples exposed to ambient air. These results also showed that the purity of water was ranked as: Milli-Q > Bottled water $>$ Tap water $>$ Distilled water, as expected because the laboratory water distillation system used collected and stored the initially clean distilled water in a vessel which was exposed to atmospheric air.

Based on Spectrex Laser Particle Counter test results reported in Table 1, the normal distilled water contained the highest number of particles, which is more than 227 counts per $\mathrm{mL}$ of particles less than $3 \mu \mathrm{m}$ in size. This value for the salt solutions which are prepared inside laminar flow cabinet using Milli-Q water was increased to 87 counts per $\mathrm{mL}$ despite the particle count initially being only 2 counts per $\mathrm{mL}$. These results suggest that, it is almost impossible to achieve a blank solution with zero particles. The lowest consistent particle count was obtained for the salt solution samples prepared using Milli-Q water inside a laminar flow cabinet, and this sample was used as blank solution in this work. In previous work, it was reported that with careful filtration, the particles can be reduced to less than 1000 counts per $\mathrm{mL}$, however it is impossible to achieve zero particles. ${ }^{44}$ In addition, it is difficult to prepare systems completely free of fine particles and nucleation sites because 
Table 1. Purity of $\mathrm{SrSO}_{4}$ solution based on particle counts and supersaturation degree.

\begin{tabular}{|c|c|c|c|c|}
\hline Solution types & $\begin{array}{l}\text { Prepared using distilled } \\
\text { water (particle counts per } \\
\mathrm{ml} \text { ) }\end{array}$ & $\begin{array}{c}\text { Prepared using Milli Q } \\
\text { water (particle counts per } \\
\mathrm{ml})\end{array}$ & $\begin{array}{l}\text { Solution filtered by } 0.22 \mu \mathrm{m} \\
\text { membrane (particle counts } \\
\text { per } \mathrm{ml} \text { ) }\end{array}$ & $\begin{array}{l}\text { Supersaturation } \\
\text { degree (S) }\end{array}$ \\
\hline Distilled water & 227 & - & - & - \\
\hline Milli Q water & - & 2 & - & - \\
\hline $0.0008 \mathrm{M} \mathrm{Sr}\left(\mathrm{NO}_{3}\right)_{2}+0.0008 \mathrm{M} \mathrm{Na}_{2} \mathrm{SO}_{4}$ & 608 & 87 & 7 & 1.86 \\
\hline $0.001 \mathrm{M} \mathrm{Sr}\left(\mathrm{NO}_{3}\right)_{2}+0.001 \mathrm{M} \mathrm{Na}_{2} \mathrm{SO}_{4}$ & 629 & 96 & 19 & 2.91 \\
\hline $0.0013 \mathrm{M} \mathrm{Sr}\left(\mathrm{NO}_{3}\right)_{2}+0.0013 \mathrm{M} \mathrm{Na}_{2} \mathrm{SO}_{4}$ & 662 & 112 & 30 & 4.91 \\
\hline $0.0015 \mathrm{M} \mathrm{Sr}\left(\mathrm{NO}_{3}\right)_{2}+0.0015 \mathrm{M} \mathrm{Na}_{2} \mathrm{SO}_{4}$ & 668 & 126 & 34 & 6.54 \\
\hline $0.002 \mathrm{M} \mathrm{Sr}\left(\mathrm{NO}_{3}\right)_{2}+0.002 \mathrm{M} \mathrm{Na}_{2} \mathrm{SO}_{4}$ & 686 & 138 & 45 & 11.63 \\
\hline $0.0025 \mathrm{M} \mathrm{Sr}\left(\mathrm{NO}_{3}\right)_{2}+0.0025 \mathrm{M} \mathrm{Na}_{2} \mathrm{SO}_{4}$ & 698 & 156 & 49 & 18.17 \\
\hline $0.005 \mathrm{M} \mathrm{Sr}\left(\mathrm{NO}_{3}\right)_{2}+0.005 \mathrm{M} \mathrm{Na}_{2} \mathrm{SO}_{4}$ & 704 & 198 & 91 & 72.67 \\
\hline
\end{tabular}

of impurities in supersaturated solutions, which are difficult to remove and act as nucleation catalysts. Also, the walls of the retaining vessel, can catalyse nucleation. The presence of some impurities can even cause inhibition of crystal growth or nucleation and so affect the rate of sulfate precipitation. ${ }^{45-47}$

By filtering the solutions prior to making up the supersaturated solutions, in a laminar flow cabinet, it was possible to reduce particle densities below 50 per $\mathrm{mL}$. This was the typical background level of particles used in this study.

The supersaturation degree of each solution in the Table 1 was calculated based on the solubility product values at $25^{\circ} \mathrm{C}$ obtained from the CRC handbook. ${ }^{48}$

The salt solutions of $\mathrm{SrSO}_{4}$ with different types of water source and degree of supersaturation were tested using a standard stirring system at $25{ }^{\circ} \mathrm{C}$ with a 3.5 $\mathrm{cm}$ length cylindrical stir bar (of $1 \mathrm{~cm}$ diameter) at a rate of $120 \mathrm{rpm}$. The induction time at which turbidity reached $0.2 \mathrm{NTU}$ was recorded. Figure 2 shows that

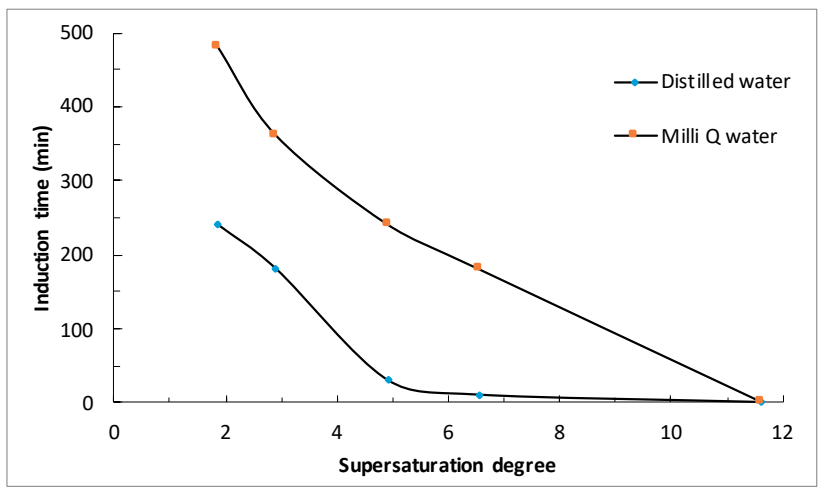

Figure 2. The induction time of $\mathrm{SrSO}_{4}$ precipitation in the solutions with different level of purity and supersaturation degrees by simple stirring $(120 \mathrm{rpm})$ at $25^{\circ} \mathrm{C}$. with increase in degree of supersaturation, the onset precipitation time drops down noticeably. The induction time is also affected by the presence of foreign particles. Solutions with the same degree of supersaturation but prepared using distilled water, precipitate in less time compared to salt solutions prepared using Milli-Q water. It was found that $\mathrm{SrSO}_{4}$ solutions in Milli-Q water with lower than 2 degrees of supersaturation had the longest induction time. By comparison, reported results show that the time of the appearance of nuclei (induction time) in water vapour is $10^{3}$ years when the supersaturation degree is at $3 .{ }^{44}$

\subsection{Effects of Stirring Rates}

The induction time for the salt precipitation in a standard stirring system is also affected by different lengths of magnetic stir bar used. As shown in Figure $3, \mathrm{SrSO}_{4}$ solutions at similar solution conditions $\left(0.0015^{2}\right.$ $\mathrm{M}^{2}$ ) were stirred at $120 \mathrm{rpm}$ at $25{ }^{\circ} \mathrm{C}$ with different lengths of stirring rod. This change in length affected the induction time. It was found that longer magnetic stir bar length reduces the induction time for precipitation. However, comparison from Figure 3 showed something quite unexpected: the induction time starts fluctuating when magnetic stirring bar lengths of $3.5 \mathrm{~cm}$ and $5.5 \mathrm{~cm}$ were used. Under the same conditions the BCE system for the precipitation of solutions provides a longer induction time of $380 \mathrm{~min}$. The solution in the $\mathrm{BCE}$ system has a stable induction time compared to a standard stirring system or even quiescent conditions. Different types of impellers show significantly different results in the precipitation process, in which parameters like different length change, line speed and the shear speed within the solution during stirring. All affect the precipitation process. ${ }^{49}$ 


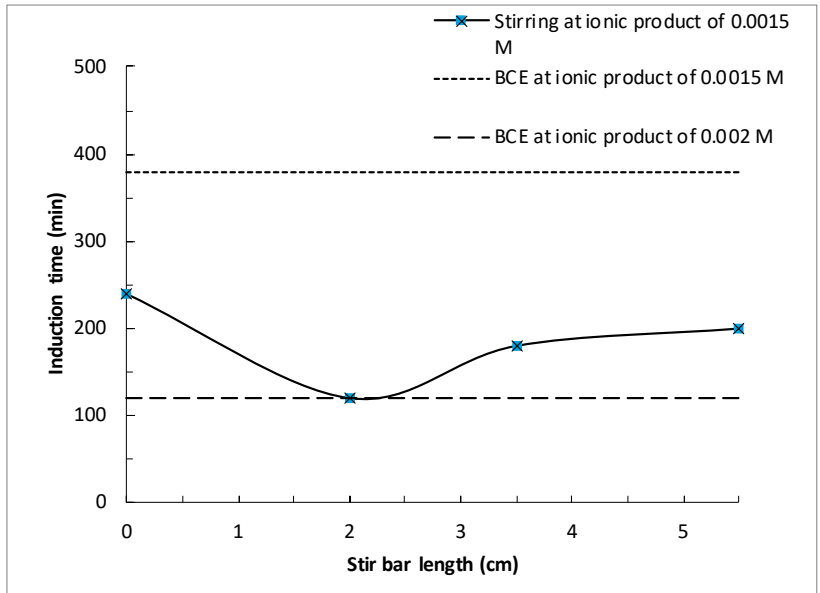

Figure 3. The induction time of $\mathrm{SrSO}_{4}$ precipitation by simple stirring (120 rpm) with different stir bar length and using a BCE at $25^{\circ} \mathrm{C}$.

\subsection{Comparison of $\mathrm{SrSO}_{4}$ precipitation using the $\mathrm{BCE}$ and a standard stirring system}

Figure 4 shows the precipitation results for $0.0015^{2}$ $\mathrm{M}^{2} \mathrm{SrSO}_{4}$ solutions in a standard stirring system with different speed of stirring and in the BCE system. In these experiments, particle growth by the precipitation process was monitored using turbidity measurements. The turbidity in a standard stirring system of $120 \mathrm{rpm}$ shows similar behaviour to a salt solution without stirring. Both slowly reach onset precipitation (turbidity $>$ 0.2 ). On the other hand, the salt solution that was placed in the same stirring system at $480 \mathrm{rpm}$ significantly increased precipitation after $60 \mathrm{~min}$. By comparison, the turbidity in the BCE system remained constant below $0.2 \mathrm{NTU}$ for more than $350 \mathrm{~min}$, even though the salt solution used in the BCE was at the same level of saturation. An increase in temperature will increase the solution solubility of $\mathrm{SrSO}_{4} \cdot{ }^{50-52}$ Initially, it was expected that continuous water evaporation within the BCE will slowly increase the supersaturation level hence causing precipitation. However, based on the results given in Figures 3 and 4, the BCE system shows a clear inhibition effect on particle growth. The rising bubbles in the BCE show complex behaviour due to coalescence and noncoalescence and bubble shape and trajectory that rise with rotational oscillation effects in the salt solution. ${ }^{53,54}$ This behaviour appears to disturb the processes involved in particle growth, even in supersaturated solutions.

Low turbidity values do not indicate definitively the absence of particles in the sample, since the turbidimeter involves a light extinction method which may not be able to detect very small particles. ${ }^{55,}{ }^{56}$ Hence, the average size of $\mathrm{SrSO}_{4}$ precipitated particles in the BCE and standard

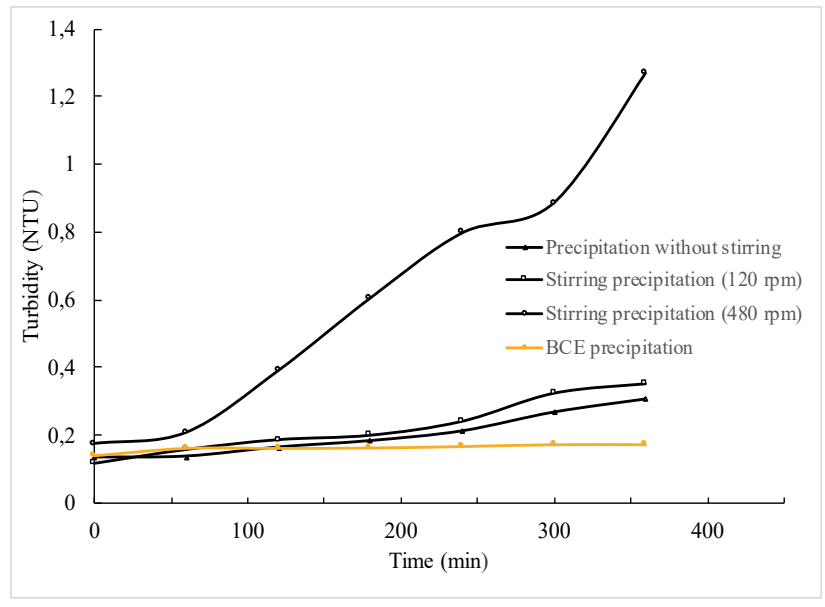

Figure 4. $\mathrm{SrSO}_{4}$ precipitation at ionic product of $0.0015^{2} \mathrm{M}^{2}$ (Supersaturation degree: 6.54) in a standard stirring process and a BCE monitored by turbidity measurements.

stirring processes were monitored using a Malvern zetasizer, as shown in Figure 5. Precipitated $\mathrm{SrSO}_{4}$ particles were detected by a Malvern Zetasizer even at the initial point of mixing of the two solutions, with particles of around $0.3 \mu \mathrm{m}$, while the turbidity of the solution was found to be below $0.2 \mathrm{NTU}$. It was shown in a previous study that once particles become large, i.e. more than about $5 \mu \mathrm{m}$ during the precipitation process, their presence can be correlated with an increase in solution turbidity. ${ }^{57}$ As a possible explanation, the salt solutions of $\mathrm{Sr}\left(\mathrm{NO}_{3}\right)_{2}$ and $\mathrm{Na}_{2} \mathrm{SO}_{4}$ mixed at the beginning of the test might was not be fully homogenous, allowing local precipitation of $\mathrm{SrSO}_{4}$ through a spontaneous heterogeneous process. ${ }^{58}$ Numerous studies have been concerned with spontaneous precipitation processes, but no satisfactory explanation has yet been accepted. ${ }^{59-63}$

The results given in Figures 4 and 5 show that increases in solution turbidity is correlated with an increase in particle size. The average size of $\mathrm{SrSO}_{4}$ particles was persistent with the SEM analysis given in Figure 7 , in which the image of the particle changes from agglomerates to microrod/pod. The precipitation process in a stirring system led to broad size particle distribution, probably due to rapid reaction. ${ }^{64}$ In comparison with $\mathrm{SrSO}_{4}$ precipitation in the BCE system, the turbidity of solution remained below $0.2 \mathrm{NTU}$ until $380 \mathrm{~min}$ and the average size of particle remained constantly below $1 \mu \mathrm{m}$. It can be seen from Figure 5 (a) that the BCE system successfully inhibits particle growth, compared to a standard stirring system. The results suggest that the BCE system for precipitation has the potential to be used as a method of controlled particle growth for the production of fine particles. 

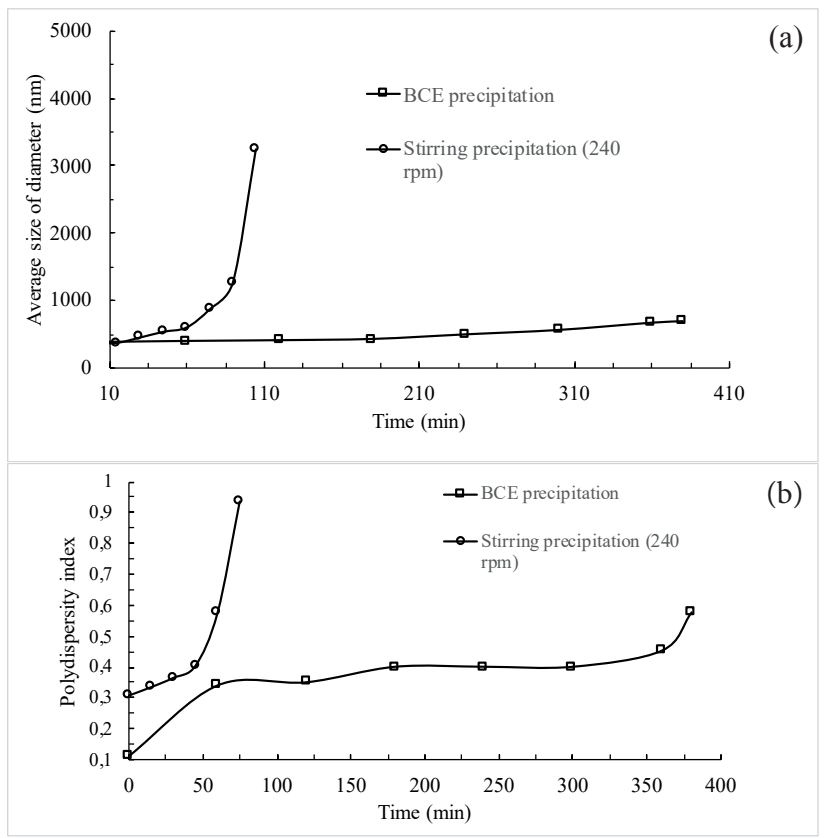

Figure 5. (a): $\mathrm{SrSO}_{4}$ precipitation at ionic product of $0.0015^{2} \mathrm{M}^{2}$ (Supersaturation degree: 6.54) in BCE and $240 \mathrm{rpm}$ stirring system by average size at around $25{ }^{\circ} \mathrm{C}$; (b): $\mathrm{SrSO}_{4}$ precipitation at ionic product of $0.0015^{2} \mathrm{M}^{2}$ (Supersaturation degree: 6.54) in BCE and $240 \mathrm{rpm}$ stirring system studied by polydispersity index (PDI) measurements at around $25^{\circ} \mathrm{C}$.

The uniformity of $\mathrm{SrSO}_{4}$ particles over time was based on the change in the Polydispersity Index (PDI) using the Malvern Zetasizer, as given in Figure 5(b). A PDI value close to 0 indicates the formation of a narrow range of particle sizes. For values that are close to 1 , it correlates with a random distribution of sizes. The precipitates of $\mathrm{SrSO}_{4}$ in the standard stirring system were expected to experience rapid growth and so a broader size distribution. After 45 mins, the PDI was around 0.5 for the standard stirring system, whereas $\mathrm{SrSO}_{4}$ particles precipitated by the $\mathrm{BCE}$ system showed a gradual increase in the PDI value. It is clear that the BCE offers significant improvement in uniformity of particle growth and a controlled size distribution.

Figure 6 and Figure 7 show images of the particles of $\mathrm{SrSO}_{4}$ formed in the precipitation process in the $\mathrm{BCE}$ system and standard stirring system, respectively. The images were captured from the initial mixing point and at $60 \mathrm{~min}$ of the BCE precipitation and at 0,60 and 75 min of the standard stirring system. As can be seen, SEM images of the precipitates formed in the standard stirring system (Figure 7) show mixtures of microrods and flower-like shapes, with sizes ranging from $1.2 \mu \mathrm{m}$ to $9.7 \mu \mathrm{m}$.

According to these results, with the same solution conditions as given in Figure 5 and Figure 6, the BCE system shows controlled and uniform particle growth compared to the standard stirring system. The pattern of the $\mathrm{SrSO}_{4}$ particles observed, consisting of microrods and flower-like shaped particles were similar to previous studies on calcium sulphate. ${ }^{26}$ The formation of $\mathrm{SrSO}_{4}$ particle growth follows a "two-step formation mechanism", in which primary microcrystals are involved in the formation of monopods, followed by the continuous growth nucleation of monopods that leads to secondary microstructure growth, through the spontaneous aggregation of pods docking on planar structures. ${ }^{65}$ The latter are formed due to their similar crystallographic orientation. ${ }^{58}$

The DLS measurements carried out for monitoring the particle size, gave further support to the inhibition effects in the BCE system, as shown in Figure 8, where

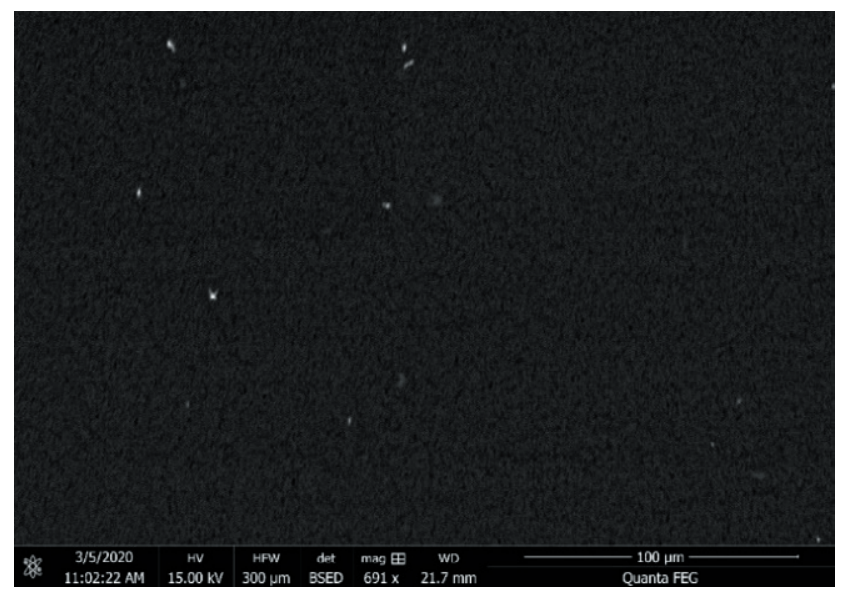

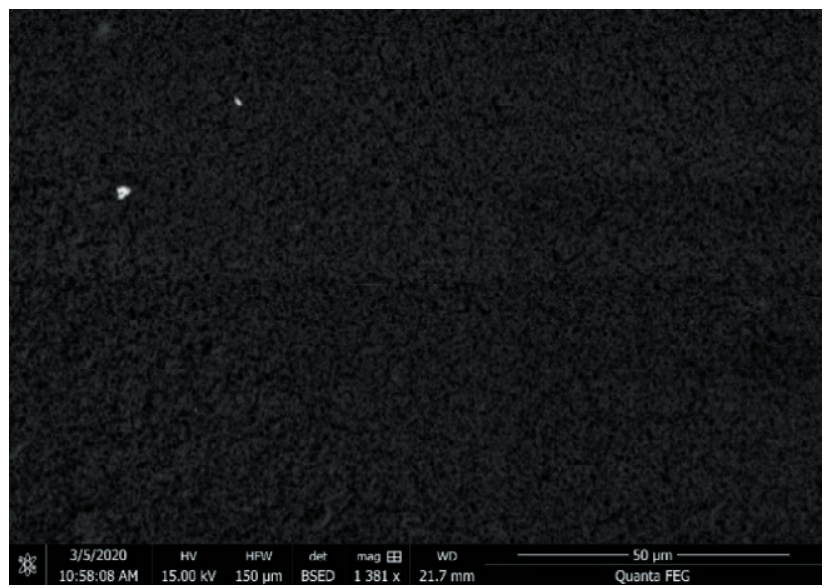

Figure 6. SEM image of $\mathrm{SrSO}_{4}$ precipitated particles at an ionic product of $0.0015^{2} \mathrm{M}^{2}$ in a BCE at $0 \mathrm{~min}$ (left), $60 \mathrm{~min}$ (right). 

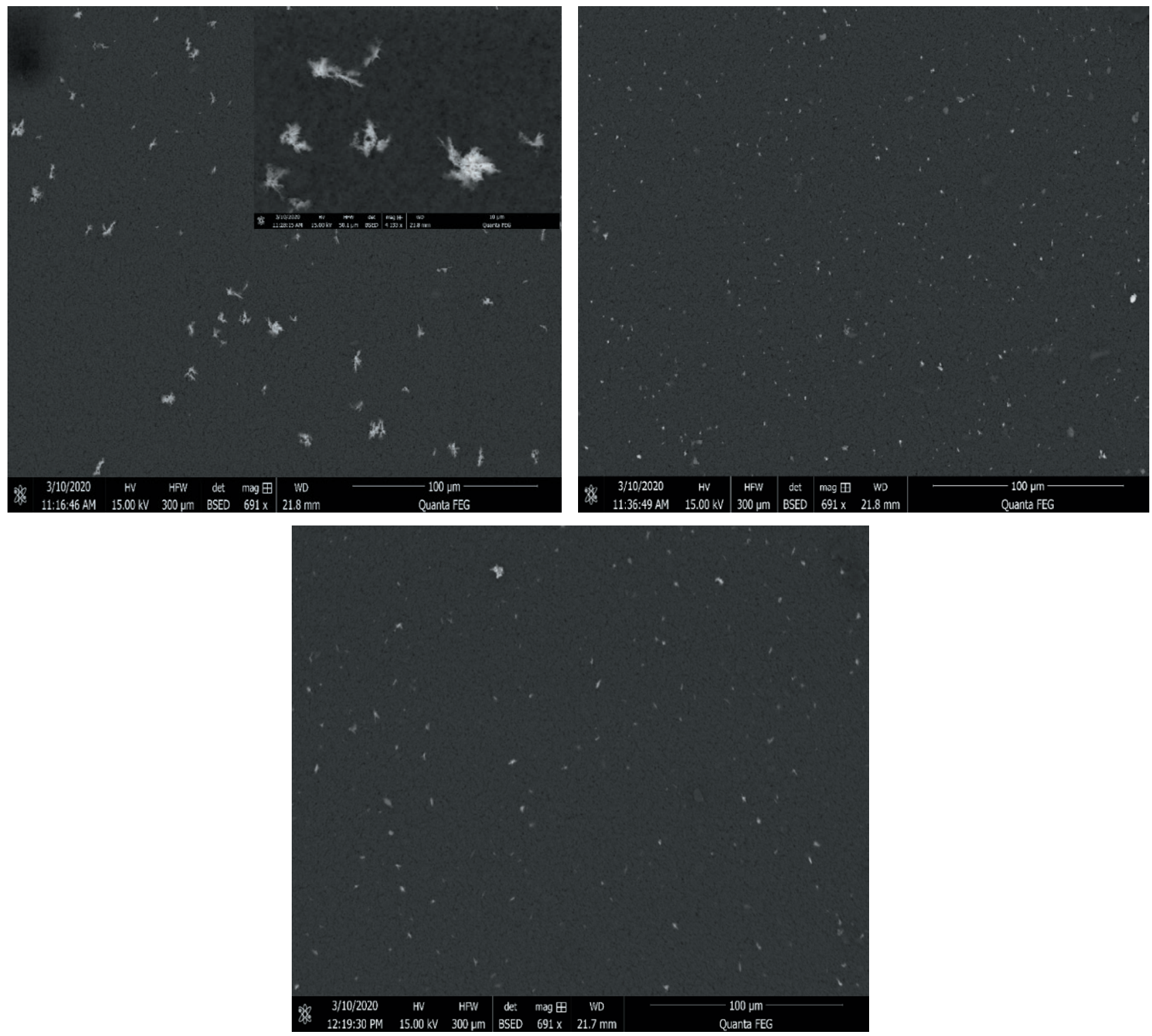

Figure 7. SEM image of $\mathrm{SrSO}_{4}$ precipitated particles at an ionic product of $0.0015^{2} \mathrm{M}^{2}$ in a standard stirring system at $0 \mathrm{~min}$ (a), $60 \mathrm{~min}$ (b) and $75 \min (c)$.

the peak size at $180 \mathrm{~min}$ remained close to the initial peak. It was found that through a continuous process, the BCE was clearly able to produce fine particles in a specific size range due to the inhibition effect apparently inherent to the BCE process.

It might be thought that the effect of electrolytes on bubble coalescence inhibition ${ }^{53,54}$ might also be related to the inhibition of precipitated particle growth. However, if there is a link it is unclear from the results presented here simply because the initial mixed salts were at concentrations significantly below those where bubble coalescence effects have previously been observed. Of course, only soluble mixed electrolytes have been studied for bubble coalescence effects but it would be a reasonable to assume that mixing $\mathrm{SrCl}_{2}$ with $\mathrm{Na}_{2} \mathrm{SO}_{4}$ should be similar to mixing $\mathrm{CaCl}_{2}$ with $\mathrm{Li}_{2} \mathrm{SO}_{4}$, both of which salts have been separately studied for their effects on bubble coalescence inhibition. For example, $\mathrm{CaCl}_{2}$ has a transition concentration (i.e. corresponding to $50 \%$ coalescence) at about $0.04 \mathrm{M}$ and $\mathrm{Li}_{2} \mathrm{SO}_{4}$ has a transition concentration at about $0.025 \mathrm{M} .^{54}$ Both these concentrations are well above even the highest concentrations (of $0.005 \mathrm{M}$ ) used in the present study and so would not be expected to significantly affect bubble coalescence in 


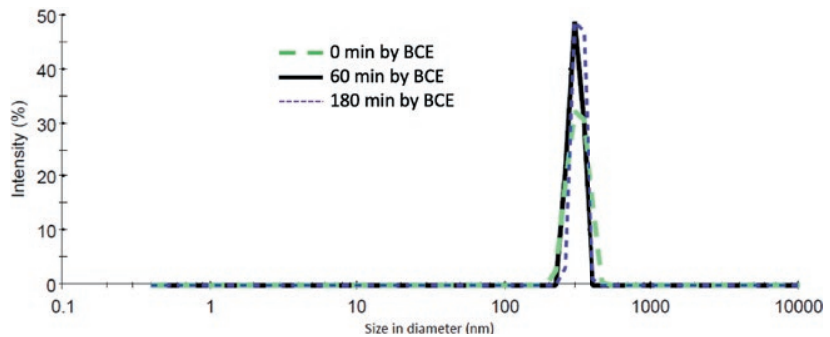

Figure 8. Size distribution of $\mathrm{SrSO}_{4}$ precipitates at ionic product of $0.0015^{2} \mathrm{M}^{2}$ in a $\mathrm{BCE}$ at $0 \mathrm{~min}, 60 \mathrm{~min}$ and $180 \mathrm{~min}$.

the column, even though at higher concentration these mixed electrolytes would be expected to affect bubble coalescence. ${ }^{66}$

In this study the precipitation levels seen in the BCE process, even for supersaturated solutions, were very low and so no attempt was made to measure the particle yield, which would be very low. It might be possible, however, to continuously remove the fine particles using, for example, a membrane nano-filtration system to increase the product yield.

This study of the comparison between the BCE process and a standard stirring system, for $\mathrm{SrSO}_{4}$ precipitates, was found to be similar to that reported earlier ${ }^{26}$ for $\mathrm{CaSO}_{4} \cdot 2 \mathrm{H}_{2} \mathrm{O}$ precipitates. Both studies suggest that the $\mathrm{BCE}$ system, due to its inhibition of particle growth, can play an important role in precipitation control, especially in particle-growth-control applications and in industrial water treatment. In addition, the technique could be used in the production of fine particles for industrial applications in ceramics, catalysis, cosmetics, pharmaceuticals and in food products. ${ }^{67}$

\section{CONCLUSIONS}

A standard stirring system and a BCE system were compared for the precipitation of $\mathrm{SrSO}_{4}$ particles from supersaturated solutions of $\mathrm{Sr}\left(\mathrm{NO}_{3}\right)_{2}$ and $\mathrm{Na}_{2} \mathrm{SO}_{4}$. The precipitation of $\mathrm{SrSO}_{4}$ in both systems was monitored by turbidity measurements, Spectrex particle counting and a DLS Malvern Zetasizer, with particle morphologies observed using SEM. It was found that the BCE system, compared to the standard stirring system, had an inhibitory effect on the precipitation induction time and the precipitate growth rate; which allows for the production of particles over a wide size range, from nanometer to micrometer. The results obtained were found to be similar to those observed earlier with $\mathrm{CaSO}_{4} \cdot 2 \mathrm{H}_{2} \mathrm{O}$ precipitation, which leads to the proposition that this might be a general property of bubble column evaporators. The BCE system potentially offers useful applications in various industrial processes, such as in the treatment of wastewater and other industries that are required to produce fine particles in a controlled manner. Particle size distribution is a key parameter in quality control. This has been highlighted in various industries, especially from material-research and processing, fresco and paper restoration.

Our study opens up insights into curious phenomena by adding a new hidden and neglected variable, the role of dissolved gas in reactivity. How this plays out in detail we outline in the Appendix.

\section{ACKNOWLEDGEMENTS}

This research was supported by funding from Breakthrough Technologies and a UNSW scholarship for AWN.

\section{REFERENCES}

1. Z. Amjad, J. Albright, Strontium Sulfate Inhibition by Biopolymers and Synthetic Polymers, Mater. Performance, 2015, 54(12), 54-58.

2. Y.D. Yeboah, M.R. Saeed, A.K. Lee, Kinetics of strontium sulfate precipitation from aqueous electrolyte solutions, J. Cryst. growth, 1994, 135(1-2), 323-330.

3. F.H. Butt, F. Rahman, U. Baduruthamal, Evaluation of SHMP and advanced scale inhibitors for control of $\mathrm{CaSO}_{4}, \mathrm{SrSO}_{4}$, and $\mathrm{CaCO}_{3}$ scales in $\mathrm{RO}$ desalination, Desalination, 1997, 109(3), 323-332.

4. H.M. Ezuber, Prediction of Strontium Sulfate Scale Formation in Oilfield Environment, J. ASTM Int., 2007, 4(6), 1-11.

5. C.C. Patton, Applied water technology, 1986.

6. A.J. Essel, B.L. Carlberg, Strontium sulfate scale control by inhibitor squeeze treatment in the Fateh field, J. Pet. Technol., 1982, 34(06), 1-302.

7. J.C. Lindlof, K.G. Stoffer, A case study of seawater injection incompatibility, J. Pet. Technol., 1983, 35(07), 1-256.

8. M. Nassivera, A. Essel, Fateh field sea water injection-water treatment, corrosion, and scale control, In Middle East Technical Conference and Exhibition, Society of Petroleum Engineers, 1979.

9. M.S.H. Bader, Sulfate removal technologies for oil fields seawater injection operations, J. Pet. Sci. Eng., 2007, 55(1-2), 93-110.

10. Z. Dai, A.T. Kan, F. Zhang, F. Yan, G. Ruan, N. Bhandari, M.B. Tomson, A Thermodynamic Model 
for The Solution Density and Mineral Solubility Predictions up to $250{ }^{\circ} \mathrm{C}, 1,500$ Bars for Na-K-Mg-Ca$\mathrm{Ba}-\mathrm{Sr}-\mathrm{Cl}-\mathrm{CO}_{3}-\mathrm{HCO}_{3}-\mathrm{SO}_{4}-\mathrm{CO}_{2}$ aq Systems. In SPE International Oilfield Scale Conference and Exhibition. Society of Petroleum Engineers.

11. F. Yan, F. Zhang, N. Bhandari, L. Wang, Z. Dai, Z. Zhang, M. Tomson, Adsorption and precipitation of scale inhibitors on shale formations, J. Pet. Sci. Eng., 2015, 136, 32-40.

12. C. Yan, A.T. Kan, W. Wang, F. Yan, L. Wang, M.B. Tomson, Sorption Study of Al-O (OH) Nanoparticle-Crosslinked Polymeric Scale Inhibitors and Their Improved Squeeze Performance in Porous Media. SPE Journal, 2014, 19(04), 687-694.

13. R.W. Howarth, A. Ingraffea, T. Engelder, Natural gas: Should fracking stop?, Nature, 2011, 477(7364), 271.

14. J. S. Al-Thuwaini, B. J. Burr, Encapsulated scale inhibitor treatment, In Middle East Oil Show and Conference. Society of Petroleum Engineers, 1997.

15. A.B.B. Merdhah, A.A.M. Yassin, Calcium and Strontium Sulfate Scale Formation Due to Incompatible Water, P. Int. Graduate Eng. Sci. (IGCES'08), 2008, 23, 24.

16. J.D. Cogan, The Removal of Barium, Strontium, Calcium and Magnesium from Hydraulic Fracturing Produced Water Using Precipitation with Traditional and Alternative Reactant Feedstocks (Doctoral dissertation, Ohio University), 2016.

17. L.O. Paugh, Marcellus shale water management challenges in Pennsylvania. In SPE Shale Gas Production Conference, Society of Petroleum Engineers, 2008.

18. A. Taha, M. Amani, Water Chemistry in Oil and Gas Operations: Scales Properties and Composition, Int. J. Org. Chem., 2019, 9(3), 130-141.

19. J. Sohaili, H.S. Shi, N.H. Zardari, N. Ahmad, S.K. Muniyandi, Removal of scale deposition on pipe walls by using magnetic field treatment and the effects of magnetic strength, J. Clean. Prod., 2016, 139, 1393-1399.

20. J. Pichtel, Oil and gas production wastewater: Soil contamination and pollution prevention, Appl. Env. Soil Sci., 2016.

21. D. Place, Water Treatment Polymers, 2017.

22. R. Bahar, M.N.A. Hawlader, Desalination: conversion of seawater to freshwater, Energy $(\mathrm{kWh} / \mathrm{m} 3 \mathrm{4}), \mathbf{2 0 1 3}$, $9(1.8), 1-8$.

23. W. Mark, The Guidebook to Membrane Desalination Technology: Reverse Osmosis, Nanofiltration and Hybrid Systems Process, Design, Applications and Economic. L'Aquila Desalination Publications, 2007.

24. A. Ozverdi, M. Erdem, $\mathrm{Cu}^{2+}, \mathrm{Cd}^{2+}$ and $\mathrm{Pb}^{2+}$ adsorption from aqueous solutions by pyrite and synthetic iron sulphide, J. Hazard. Mater., 2006, 137(1), 626632.

25. M. Shahid, C. Fan, R.M. Pashley, Insight into the bubble column evaporator and its applications, Int. Rev. Phys. Chem., 2016, 1(135), 143-185.

26. C. Fan, R.M. Pashley, The controlled growth of calcium sulfate dihydrate (gypsum) in aqueous solution using the inhibition effect of a bubble column evaporator, Chem. Eng. Sci., 2016, 142, 23-31.

27. M. S. Atone, S. V. Moharil, S. M. Dhopte, P. L. Muthal, V. K. Kondawar, Synthesis and characterization of $\mathrm{SrSO}_{4}$ : $\mathrm{Mo}, \mathrm{Tb}$ thermoluminescent phosphor. physica status solidi (a), 1999, 174(2), 521-526.

28. T. Murakami, J.H. Ouyang, K. Umeda, S. Sasaki, Hightemperature friction properties of $\mathrm{BaSO}_{4}$ and $\mathrm{SrSO}_{4}$ powder films formed on $\mathrm{Al}_{2} \mathrm{O}_{3}$ and stainless steel substrates, Mater. Sci. Eng., A, 2006, 432(1-2), 52-58.

29. R. Giorgi, C. Bozzi, L. Dei, C. Gabbiani, B.W. Ninham, P. Baglioni, Nanoparticles of $\mathrm{Mg}(\mathrm{OH})_{2}$ : synthesis and application to paper conservation, Langmuir, 2005, 21(18), 8495-8501.

30. Y. Kimura, Rare earth phosphate particle and its production, Japan Kokai Tokkyo Koho, 1996, JP H08143305.

31. S.A. Khan, A. Gunther, M.A. Schmidt, K.F. Jensen, Microfluidic synthesis of colloidal silica, Langmuir, 2004, 20(20), 8604-8611.

32. T. Ogihara, M. Yabuuchi, T. Yanagawa, N. Ogata, K. Yoshida, N. Nagata, U. Maeda, Preparation of monodispersed, spherical ferric oxide particles by hydrolysis of metal alkoxides using a continuous tube-type reactor, Adv. Powder Technol., 1997, 8(1), 73-84.

33. M. Raudino, F. Sarri, D. Tatini, M. Ambrosi, G.D. Aloisi, B.W. Ninham, L. Dei, P.L. Nostro, The Effect of Temperature and Magnetic Field on the Precipitation of Insoluble Salts of Alkaline Earth Metals, J. Solution Chem., 2020, 49(3), 289-305.

34. M. A. Salman, M. Safar, G. Al-Nuwaibit, The Effect of Magnetic Treatment on Retarding Scaling Deposition, The Online J. Sci. Technol., 2015, 5(3), 62-77.

35. B. J. Mason, The nuclei of atmospheric condensation, Geofisica pura e applicata, 1957, 36(1), 9-20.

36. P. A. Barata, M. L. Serrano, Salting-out precipitation of potassium dihydrogen phosphate (KDP). I. Precipitation mechanism, J. Cryst. Growth, 1996, 160(3-4), 361-369.

37. D.F. Jacques, B.I. Bourland, A study of solubility of strontium sulfate, Soc. Pet. Eng. J., 1983, 23(02), 292300.

38. D. Feng, C. Aldrich, H. Tan, Treatment of acid mine water by use of heavy metal precipitation and ion exchange, Miner. Eng., 2000, 13(6), 623-642. 
39. M. Li, Removal of divalent cations from marcellus shale flowback water through chemical precipitation (Doctoral dissertation, University of Pittsburgh), 2011.

40. T. Chen, P. Chen, H. Montgomerie, T. Hagen, R. Benvie, Q. Guo, X. Yang, Do We Need Higher Dose Scale Inhibitors to Inhibit Scale under Turbulent Conditions? Insight into Mechanisms and New Test Methodology, In SPE International Oilfield Scale Conference and Exhibition, Soc. Pet. Eng. J., 2014.

41. F. Yan, N. Bhandari, F. Zhang, G. Ruan, Z. Dai, Y. Liu, M. Tomson, Scale Formation and Control Under Turbulent Conditions, In SPE International Oilfield Scale Conference and Exhibition, Soc. Pet. Eng. J., 2016.

42. F. Yan, Z. Dai, G. Ruan, H. Alsaiari, N. Bhandari, F. Zhang, M. Tomson, Barite scale formation and inhibition in laminar and turbulent flow: A rotating cylinder approach, J. Pet. Sci. Eng., 2017, 149, 183-192.

43. F. Yan, F. Zhang, N. Bhandari, G. Ruan, H. Alsaiari, Z. Dai, A. Kan, The Effect of Turbulence on Mineral Scale Control in Oilfield, In SPE International Conference on Oilfield Chemistry, Soc. Pet. Eng. J., 2017.

44. J. W. Mullin, Crystallization, Elsevier, 2001.

45. A. Hina, G.H. Nancollas, Precipitation and dissolution of alkaline earth sulfates: kinetics and surface energy, Rev. Miner. Geochem., 2000, 40(1), 277-301.

46. S.K. Hamdona, S.M. Hamza, Influence of polyphosphonates on the precipitation of strontium sulfate (Celestite) from aqueous solutions, J. Taibah Uni. Sci., 2009, 2(1), 36-43.

47. M. C. Van der Leeden, D. Kashchiev, G. M. Van Rosmalen, Effect of additives on nucleation rate, crystal growth rate and induction time in precipitation, $J$. Cryst. Growth, 1993, 130(1-2), 221-232.

48. D. R. Lide, H. P. R. Fredrikse, CRC handbook of chemistry and physics, CRC Press, Boca Raton, FL. CRC handbook of chemistry and physics, 75th ed. CRC Press, Boca Raton, FL, 1994.

49. W. Beckmann, Crystallization: basic concepts and industrial applications, John Wiley \& Sons, 2013.

50. D. F. Jacques, B. I. Bourland, A study of solubility of strontium sulfate, Soc. Pet. Eng. J., 1983, 23(02), 292300.

51. E.J. Reardon, D.K. Armstrong, Celestite $\left(\mathrm{SrSO}_{4}\right.$ (s) solubility in water, seawater and $\mathrm{NaCl}$ solution, Geochim. Cosmochim. Acta, 1987, 51(1), 63-72.

52. R. D. Howell, K. Raju, G. Atkinson, Thermodynamics of "scale" mineral solubilities. 4. Experimental measurements of strontium sulfate (s) in water and aqueous sodium chloride from 25 to $250{ }^{\circ} \mathrm{C}$ and from 1 to 500 bar, J. Chem. Eng. Data, 1992, 37(4), 464-469.
53. V.S.J. Craig, B.W. Ninham, R.M. Pashley, Effect of electrolytes on bubble coalescence, Nature, 1993, 364(6435), 317-319.

54. V. S. J. Craig, B. W. Ninham, R. M. Pashley, The effect of electrolytes on bubble coalescence in water, J. Phys. Chem., 1993, 97(39), 10192-10197.

55. N. Brown, Particle size analysis of large, transparent alumina trihydrate particles by turbidimetry, Powder Technol., 1971, 4(4), 232-234.

56. S. He, J. E. Oddo, M. B. Tomson, The Nucleation kinetics of strontium sulfate in $\mathrm{NaCl}$ solutions up to $6 \mathrm{~m}$ and $90 \mathrm{C}$ with or without inhibitors, J. Colloid Interface Sci., 1995, 174(2), 327-335.

57. W. He, J. Nan, Study on the impact of particle size distribution on turbidity in water, Desalination and Water Treat., 2012, 41(1-3), 26-34.

58. I. X. Malollari, P. G. Klepetsanis, P. G. Koutsoukos, Precipitation of strontium sulfate in aqueous solutions at $25^{\circ} \mathrm{C}, \mathrm{J}$. Cryst. Growth, 1995, 155(3-4), 240-246.

59. A. E. Nielsen, Homogeneous nucleation in barium sulfate precipitation, Acta Chemica Scandinavica, 1961, 15(2), 441.

60. A. E. Austin, J. F. Miller, N. A. Richard, J. F. Kircher, Precipitation of calcium sulfate from sea water at high temperatures, Desalination, 1975, 16(3), 331-344.

61. Z. Amjad, Environment Treatment \& Control MP, 1989.

62. F. H. Butt, F. Rahman, U. Baduruthamal, Evaluation of SHMP and advanced scale inhibitors for control of $\mathrm{CaSO}_{4}, \mathrm{SrSO}_{4}$, and $\mathrm{CaCO}_{3}$ scales in $\mathrm{RO}$ desalination, Desalination, 1997, 109(3), 323-332.

63. G. R. Campbell, G.H. Nancollas, Crystallization and dissolution of strontium sulfate in aqueous solution, J. Phy. Chem., 1969, 73(6), 1735-1740.

64. M. Kawase, K. Miura, Fine particle synthesis by continuous precipitation using a tubular reactor, $A d v$. Powder Technol., 2007, 18(6), 725-738.

65. J. Sun, R. Sun, Z. Xia, H. Du, Facile room temperature morphology-controlled synthesis of $\mathrm{SrSO}_{4}$ microcrystals, Cryst. Eng. Comm., 2012, 14(3), 11111116.

66. C. L. Henry, C. N. Dalton, L. Scruton, V.S.J Craig, Ion-specific coalescence of bubbles in mixed electrolyte solutions, J. Phys. Chem., 2007, (111), 1015-1023.

67. J. Toth, A. Kardos-Fodor, S. Halász-Péterfi, The formation of fine particles by salting-out precipitation, Chem. Eng. Process.: Process Intensification, 2005, 44(2), 193-200.

68. B. W. Ninham, R. M. Pashley, P. Lo Nostro, Surface forces: Changing concepts and complexity with dissolved gas, bubbles, salt and heat, Curr. Opin. Colloid Interface Sci., 2016, 27, 25-32. 
69. M. Taseidifar, J. Anthony, R.M. Pashley, Prevention of Cavitation in Propellers, In press: Substantia: An International Journal of the History of Chemistry, 2020.

70. H. K. Kim, E. Tuite, B. Norden, B.W. Ninham, Coiondependence of DNA nuclease activity suggests hydrophobic cavitation as a potential source of activation energy Eur. Phys. J. E, 2001, 4, 411-417.

71. S. V. Gudkov, G. A. Lyakhov, V.I. Pustovoy, I.A. Shcherbakov, Influence of Mechanical Effects on the Hydrogen Peroxide Concentration in Aqueous Solutions, Phys Wave Phenom, 2019, 27(2), 141-144.

72. B. W. Ninham, P. Lo Nostro, Unexpected Properties of Degassed Solutions, J. Phy. Chem. B, 2020, 124(36), 7872-7878.

73. A. E. Voinescu, D. Touraud, A. Lecker, A. Pfitzner, W. Kunz, B. W. Ninham, Mineralization of $\mathrm{CaCO}_{3}$ in the Presence of Egg White Lysozyme, Langmuir, 2007, 23, 12269-12274.

74. B. P. Reines, B.W. Ninham, Structure and function of the endothelial surface layer: unraveling the nanoarchitecture of biological surfaces, Quarterly Rev. Biophys., 2019, 52, 1-11.

75. A. G. Sanchis, R. M. Pashley, B. W. Ninham, Virus and bacteria inactivation by $\mathrm{CO}_{2}$ bubbles in solution, NPJ Clean Water, 2019, (2) Number 1.

76. A. G. Sanchis, L. Jin, Evaluation of the new energyefficient hot bubble pilot plant (HBPP) for water sterilization from the livestock farming industry, Water Resour. Ind., 2020, 24, 100135.

\section{APPENDIX \\ FACTORS CONTROLLING PRECIPITATION}

The "reaction" Eq. (1) for the formation of particles is impeccably correct.

$\mathrm{Sr}^{2+}{ }_{(\mathrm{aq})}+\mathrm{SO}_{4}{ }_{(\mathrm{aq})} \rightleftarrows \mathrm{SrSO}_{4(\mathrm{~S})}$

However, the reactants have no respect for equations on pieces of paper and something more inscrutable lies beneath it. We note first that the entire field of physical chemistry is undergoing revision due to sins of omission and commission at this time. ${ }^{68}$ The problem of Hofmeister effects with all its consequences is on the way to resolution. But the more important issue is the omission in classical theory of the effects of dissolved gas. The omission is monumental in its consequences, a fact still only dimly perceived.

We showed the effects of cavitation on a propeller which is explored in detail in a paper in this Substan- tia Journal issue. ${ }^{69}$ The reactions that produce propeller corrosion is due to the collapse of nanobubbles, that are accompanied by free radical production. The same free radicals are also produced by spontaneous cavitation in the active sites of an enzyme and are due to cooperative harnessing of all the weak van der Waals and other molecular forces to produce a chemical energy available to do the job. ${ }^{70}$

Nanobubbles containing reactive hydrogen peroxide are produced even by shaking, without any need for heavy sonication. ${ }^{70,71}$

In this paper both stirring at different speeds and turbulence accompanying the BCE process would therefore be expected to produce nanobubbles of different sizes and stability. These should also produce sites for the selective adsorption of both anions and cations and enhanced reactivity.

We have already discussed another related fundamental work that studies the effects of magnetic fields and temperature on the precipitation of alkaline earth metal salts. ${ }^{33}$ The magnetic field seems too small an influence here. But who knows? Permanent magnets placed outside steel pipes prevent scaling. This works but no one knows why.

The effects of temperature are also large and specific in Ref [33] and that too can be put into the nanobubble causality camp. Water is generally agreed to lose its hydrogen bonding between $80-90^{\circ} \mathrm{C}$. So, our elusive nanobubbles will be different at higher temperatures, as will specific ion adsorption and reactivity.

Of all the different methods used to produce monodisperse nano or micro particles, the work Ref [29] is closest. In our study we used a mixture of

$0.005 \mathrm{M} \mathrm{Sr}\left(\mathrm{NO}_{3}\right)_{2}+0.005 \mathrm{M} \mathrm{Na}_{2} \mathrm{SO}_{4}$

and precipitated out particles of strontium sulphate. In Ref [29] the precipitated particles were $\mathrm{Mg}(\mathrm{OH})_{2}$. The initial solution contained soluble salts of magnesium in a background of sodium hydroxide. The counterions of the magnesium source salts affect the size and the specific surface area of crystallites with a trend that follows a Hofmeister series of anions: (sulfate $<$ chloride $<$ nitrate $<$ perchlorate). It was also shown that depending on the concentration of background salt the precipitated particles could vary in size from a micron to zero radius.

The two experiments are difficult to compare. With $\mathrm{Mg}(\mathrm{OH})_{2}$ the background of indifferent anions are at high concentrations $0.2,0.4,1$, and $2 \mathrm{M}$. The solutions were vigorously stirred as for our case. The same controlled variability in particle size can be achieved with sugars in solution. 
The concentrations are well above the 'critical concentration' for bubble-bubble fusion inhibition..$^{53,54,66}$ So, it might be thought reasonable to assign the phenomena of size variability to 'water structure'.

By contrast, the situation for strontium sulfate here the concentrations were typically low at about $0.005 \mathrm{M}$ and hence water structure cannot possibly be an issue.

This throws us firmly back into the wide-open arena of nanobubbles.

Our reference [72] brings the case into strong contention as a crucial, long-neglected hidden variable.

Finally, we remark on two matters that mineralization of calcium carbonate in the presence of proteins is probably the most used chemical reaction in nature by weight, being responsible for shells of all invertebrates. ${ }^{73}$ This mineralization is of much interest too because of alarms about climate change.

Ref [73] is exceptionally important as it produced amorphous calcium carbonate for the first time. Ref [74] opens up a new arena too in medicine and biology.

Carbon dioxide foam of nanobubbles is the key component of a crucial new organ in the body, the Endothelial Surface Layer. It plays a key role in protection against viruses and cab and is being used industrially for sterilisation of water. See Editorial and Ref $[75,76]$. 